\title{
GIS Mapping of TRMM Precipitation Data (NASA) over Bhandara District
}

\author{
Sumedh R. Kashiwar ${ }^{1 *}$, Usha R. Dongarwar ${ }^{2}$, Manik Chandra Kundu ${ }^{1}$, \\ Sudarshan Awatade ${ }^{3}$, Dileep Kumar ${ }^{4}$, Lopchand Dongarwar ${ }^{5}$ and Hemkalyan Verma ${ }^{3}$ \\ ${ }^{1}$ Department of Soil Science and Agricultural Chemistry, Palli Shiksha Bhavana (Institute of \\ Agriculture), Visva-Bharati, Sriniketan, West-Bengal-731236, India \\ ${ }^{2}$ Krishi Vigyan Kendra, Sakoli, Bhandara, Maharashtra-441802, India \\ ${ }^{3}$ Palli Shiksha Bhavana (Institute of Agriculture), Visva-Bharati, Sriniketan, \\ West-Bengal-731236, India \\ ${ }^{4}$ Micro Nutrient Research (ICAR), Anand Agricultural University, Anand, \\ Gujarat-388110, India \\ ${ }^{5}$ Dr. Panjabrao Deshmukh Krishi Vidyapeeth, Akola, Maharashtra-444104, India \\ *Corresponding author
}

\section{A B S T R A C T}

This study aimed to verify the performance of the information produced by the Ground rain gauge stations and TRMM (Tropical Rainfall Measurement Mission) of NASA on the

\section{Keywords}

TRMM, NASA, Rainfall, Bhandara

Article Info

Accepted:

06 July 2018

Available Online:

10 August 2018
Bhandara region of Maharashtra, India, based on a comparison of rainfall data from IMD (Indian Meteorological Department). The comparison was done by comparing spatially aggregated information from both sources. In order to analyze the results, Coefficient of determination $\left(\mathrm{R}_{2}\right)$, MBE, Root Mean Square Error (RMSE) and NRMSE has been measured. Observed rainfall and TRMM rainfall values for Jun-Sept period are comparable. There is high consistency between the estimates of these two data sets during 2008 to 2015 than the earlier seven years period. It was found that the relative differences were in the range of $-20 \%$ to $20 \%$ for both data sets. Analysis of both data sets has resulted the $30 \%$ of overestimated measurements. The TRMM values are to the higher side in the years 2000 to 2017 whereas there is hardly any difference in-between. The results indicate very good linear relationship between the two rainfall datasets, with the determination coefficient $R_{2}=0.6697$ with the regression line slope 0.7813 .

\section{Introduction}

The variability of the Indian monsoon affects the agriculture food grain production, industry and generation of hydroelectric power, causing severe strain on the national economy. Large parts of the country are severely affected due to deficit monsoon rainfall and
Government of India spends large amount of money on providing relief in affected areas. Significance of Monsoon to Indian economy and as major global circulation constraint has encouraged many scientists to study the variability of Indian monsoon. Precipitations and subsequently water availability, are the most important indicators in determining the 
weather and climate conditions of a region. It is extremely useful to have knowledge about quantitative rainfall information and its distribution over time in addition, knowing quantitative rainfall information has a vital role in identifying the need for additional irrigation of several crops (Massagli, et al., 2011). The traditional techniques of rainfall measurement which is performed with ground rain gauges and these instruments have deficiencies in the representation of rainfall distribution in larger areas, because they are punctual instruments that cover an area of about $10^{-1} \mathrm{~m}^{2}$ (Fensterseifer, 2013). To overcome this issue, a high density of rain gauges would be required to appropriately represent the rainfall behavior of a particular region and for countries having large provincial areas, it would be impracticable due to the high costs of rainfall monitoring. From the last fifteen years or so, there is predominant decrease in the rainfall activity over the Indian region resulting in severe drought conditions. Even the remaining years shown decrease in average annual rainfall. This triggered depletion in surface as well as groundwater levels, whereas demand for water is continuously increasing with the increasing population. Being an agricultural country, accurate prediction of this monsoon rainfall is essential for agricultural purposes. Due to uneven distribution of the spatial and temporal rainfall, it is difficult to determine the rainfall over the region. Weather and climate forecast studies require this precise data in modeling the dynamic surface hydrologic state but with highest possible resolution (Indu et al., 2014). A lot of remote sensing products in rainfall assessment are available in detailed spatial and temporal resolutions. The remote sensing can contribute to continuous representation of the distribution of rainfall data (Santos, 2014).The Tropical Rainfall Measurement Mission (TRMM) was launched on November 27, 1997 jointly associated by National Aeronautics and Space Administration
(NASA) of US and the National Space Development Agency (NASDA) of Japan. It is the first mission dedicated for measuring tropical and subtropical rainfall (Simpson, et al., 1988 and Kummerow, et al., 2000). The main aim of this mission was to measure tropical and subtropical rainfall through microwave and visible infrared sensors, and this also included the first space borne rain radar. The primary instruments for measuring precipitation were the Precipitation Radar, the TRMM Microwave Imager (TMI), and the Visible and Infrared Scanner. Studies performed by Hiroshima (1999), Kummerowa et al., (2000) and Flaming (2004) demonstrated the quality of the results obtained by the mission. Due to this success, another generation of precipitation satellite was projected. The Global Precipitation Measurement satellite was launched in February 2014 promising more refined precipitation data both in terms of time and as in space (NASA, 2011). Currently more than 5000 rain gauge stations all over India is gathering rainfall data during the monsoon season. Even then rainfall data of some remote places is questionable and are difficult to access for administrative or technical purposes such as for operational hydrological forecasting a real time data is needed which is not possible due to incomplete data set. Satellite-based rainfall products are a valuable alternative to overcome such situations.

\section{Materials and Methods}

Present study was carried out in the Bhandara district of Maharashtra, India comprises seven sub districts namely Bhandara $\left(79.6184^{\circ} \mathrm{E}\right.$ $\left.21.1696^{\circ} \mathrm{N}\right), \quad$ Mohadi $\quad\left(79.6596^{\circ} \mathrm{E}\right.$ 21.30912 $\left.{ }^{\circ} \mathrm{N}\right), \quad$ Tumsar $\quad\left(79.73238^{\circ} \mathrm{E}\right.$ $\left.21.3833^{\circ} \mathrm{N}\right), \quad$ Lakhani $\quad\left(79.82027^{\circ} \mathrm{E}\right.$ $\left.21.05558^{\circ} \mathrm{N}\right), \quad$ Sakoli $\quad\left(79.98232^{\circ} \mathrm{E}\right.$ $\left.21.07096^{\circ} \mathrm{N}\right), \quad$ Lakhandur $\quad\left(79.88756^{\circ} \mathrm{E}\right.$ $\left.20.77721^{\circ} \mathrm{N}\right)$ and Pauni $\left(79.6541^{\circ} \mathrm{E}\right.$ $\left.20.80032^{\circ} \mathrm{N}\right)$. The base map has been prepared 
from the Survey of India Topographic sheets on 1:50,000 scale. Monthly rainfall data of rain gauge for the period of 18 years from 2000 to 2017 has been collected from Indian Meteorological Department, Pune and Tropical Rainfall Measurement Mission (TRMM). Seven rain gauge stations have been taken into consideration for calculating long term mean monthly, seasonal and annual rainfall pattern and these have been analyzed. The considered data sets known as 3B43 are routinely produced by the tropical rainfall measuring mission (TRMM) from passive microwave and infrared recordings. The data are made available at no charge by the TRMM mission. This product is an optimal combination of various high quality microwave estimates to adjust infrared estimates from high-frequency geostationary observations (http://trmm.gsfc.nasa.gov/). The TRMM rainfall data is useful in finding the rain location and intensity of rainfall. The comparison of observed rainfall and TRMM rainfall was not done station by station data but average annual rainfall over the entire region on sub-divisional scale has been compared with TRMM data. It was found that the inverse squared distance method in GIS software gave better results compared to the other interpolation methods. In this method, the weighted rainfall is calculated from the rain gauge data by its distances from the interpolating point. This helps in improving the accuracy of the spatial interpolation in regions having low density of rain gauge networks (Fig. 1).

To assess the satellite rainfall estimates with the observed rainfall following statistical measures were used:

Coefficient of determination $\left(\mathrm{R}_{2}\right)$ : It is the degree of linear association between the observed rainfall and satellite derived rainfall. The goodness of fit of the relation is evaluated by $R_{2}$ (Eq.1)

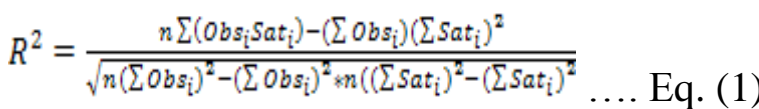

Where $\mathrm{R}_{2}$ is the coefficient of determination, $\mathrm{Obs}_{i}$ the observed rainfall measurements, $\mathrm{Sat}_{i}$ the satellite rainfall estimates, and $\mathrm{n}$ the number of data pairs.

Mean Bias Error (MBE): It is the simple ratio of average satellite rainfall estimation to average observed rainfall estimation values (Eq.2). A bias of 1.1 means the satellite rainfall is $10 \%$ higher than the average

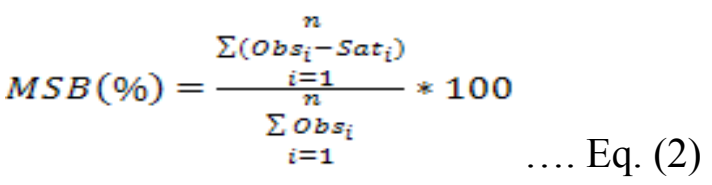

Root Mean Square Error (RMSE): measures are used to know the difference between the distributions of the observed rainfall with that of satellite rainfall estimation. It calculates a weighted average error, with reference to the square of the error. RMSE is useful when large errors are undesirable. The lower the RMSE score, the closer the satellite rainfall estimation represents the observed ground rainfall measurement (Eq.3).

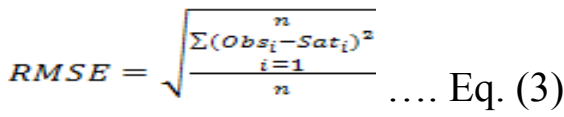

Where RMSE is the root mean square error, $\mathrm{Obs}_{i}$ the observed rainfall measurements, $\mathrm{Sat}_{i}$ the satellite rainfall estimates, and $\mathrm{n}$ the number of data pairs. As the RMSE is an inappropriate measure for mean error and can be easily misinterpreted (Willmott et al., 2005) in this study, NRMSE (Eq.4) is also used to evaluate the accuracy of TRMM precipitation.

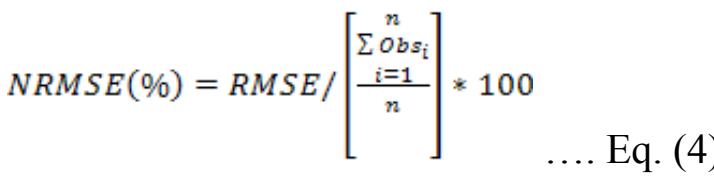


The NRMSE, is considered to be excellent if it is $<10 \%$, good if $10-20 \%$, fair if $20-30 \%$, and poor $>30 \%$ (Jamieson, et al., 1991 and Signoretto et al., 2011).

Pearson product moment correlation (Sample Correlation Coefficient):

$r=\frac{\sum(x-\bar{x})(y-\bar{y})}{\sqrt{\sum(x-\bar{x})^{2}} \sqrt{\Sigma(y-\bar{y})^{2}}} \ldots$ Eq. $(5)$

The correlation should be between +1 and -1 showing perfect increasing or decreasing linear relationship and the values in between indicates the degree of linear relationship between estimated and observed values. If $r$ is 0 means there is no linear relationship between the variables.

\section{Results and Discussion}

In India more than $80 \%$ of rainfall is received during the monsoon season Jun-Sept and the analysis of this study compares the seasonal rainfall estimates of the TRMM data with rain gauge rainfall data over the Bhandara Districts during 2000 to 2017. The Seasonal rainfall (Jun-Sept) statistics of TRMM 3B43and rain gauge data for the Bhandara district as well sub-district region are given in Table 1. The observed rainfall and TRMM rainfall readings for Jun-Sept time period are comparable (Table 1 and 2).

The TRMM values are high as compared to Rain gauge stations whereas there is some difference between the two data sets. The mean rainfall values are showing a few number differences in between, indicating that the error in total amount is negligible (Table 4). On the other hand the comparison of rainfall standard deviation calculated from the two data sets has shown a difference as the supreme seasonal rainfall in case of rain gauge station is $404.55 \mathrm{~mm}$ in and in TRMM rainfall is $562.42 \mathrm{~mm}$. The minimum seasonal rainfall was $179.65 \mathrm{~mm}$ in rain gauge station and $322.30 \mathrm{~mm}$ in TRMM. The level of confidence at $95 \%$ was 32.10 in Rain gauge and 33.62 in TRMM (Table 3). To further evaluate the relationships between the two data sets, the scatter plots of seasonal TRMM rainfall against rain gauges rainfall data is shown in Figure 2.

The results indicate very good linear relationship between the two rainfall datasets, with the determination coefficient $\mathrm{R}_{2}=0.669$ with the regression line slope 0.7813 .

The TRMM satellite can capture the rainfall characterization in comparison with the measurement from traditional rain gauges rainfall. For that reason, to recognize the accurateness of spatial distribution of the TRMM rainfall data, the spatial distribution of seasonal rainfall for all the years have been compared.

It can be seen there is some dissimilarity in the spatial distribution between the rain gauge stations and TRMM rainfall data of Bhandara district. It may be the effect of topography throughout the study area. Therefore, it can be concluded that while undertaking the precipitation studies in this particular region, it is necessary to investigate the effect of topography to have more accuracy in rainfall pattern by using different remotely sensed data because TRMM also has some computational errors. The validity of TRMM data in the Bhandara region was compared with monthly rainfall variations and almost similar variations were observed in both the data sets at all the sub-districts.

The kurtosis and Skewness in statistical analysis was -0.78, 0.41 (Rain gauge station) and $-0.29,0.66$ in TRMM respectively (Table 4). Relationship between two rainfall data also proved the validation of TRMM data (Mishra, et al., 2009) over the Indian region. 
Table.1 Seasonal rainfall observed in Rain gauge and TRMM data sets of Bhandara District (2000-2008)

\begin{tabular}{|c|c|c|c|c|c|c|c|c|c|c|c|c|c|c|c|c|c|c|c|c|c|}
\hline \multirow[t]{2}{*}{ Station } & \multirow[t]{2}{*}{ Lon. } & \multirow[t]{2}{*}{ Lat. } & \multirow[t]{2}{*}{ Annual } & \multicolumn{2}{|c|}{2000} & \multicolumn{2}{|c|}{2001} & \multicolumn{2}{|c|}{2002} & \multicolumn{2}{|c|}{2003} & \multicolumn{2}{|c|}{2004} & \multicolumn{2}{|c|}{2005} & \multicolumn{2}{|c|}{2006} & \multicolumn{2}{|c|}{2007} & \multicolumn{2}{|c|}{2008} \\
\hline & & & & $\mathrm{R} / \mathrm{G}$ & TRMM & $\mathrm{R} / \mathrm{G}$ & TRMM & $\mathrm{R} / \mathrm{G}$ & TRMM & $\mathrm{R} / \mathrm{G}$ & TRMM & $\mathrm{R} / \mathrm{G}$ & TRMM & $\mathrm{R} / \mathrm{G}$ & TRMM & $\mathrm{R} / \mathrm{G}$ & TRMM & $\mathrm{R} / \mathrm{G}$ & TRMM & $\mathrm{R} / \mathrm{G}$ & TRMM \\
\hline Bhandara & 79.6184 & 21.1696 & 1375.60 & 312.28 & 340.65 & 390.70 & 432.56 & 397.48 & 402.26 & 534.03 & 355.89 & 290.30 & 303.59 & 317.13 & 486.55 & 242.23 & 355.87 & 253.60 & 446.39 & 243.88 & 348.95 \\
\hline Mohadi & 79.6596 & 21.30912 & 1375.60 & 306.63 & 316.39 & 509.60 & 384.24 & 269.55 & 393.03 & 236.45 & 366.19 & 160.35 & 307.08 & 410.55 & 453.82 & 203.30 & 423.61 & 272.60 & 449.91 & 227.08 & 339.00 \\
\hline Tumsar & 79.73238 & 21.3833 & 1375.60 & 246.55 & 316.39 & 225.28 & 384.24 & 245.33 & 393.03 & 303.23 & 366.19 & 123.38 & 307.08 & 420.05 & 453.82 & 259.98 & 423.61 & 266.25 & 449.91 & 228.75 & 339.00 \\
\hline Pavni & 79.6541 & 20.80032 & 1346.30 & 239.95 & 414.54 & 199.35 & 477.38 & 246.28 & 385.55 & 281.50 & 395.92 & 155.58 & 310.03 & 302.80 & 437.72 & 241.13 & 358.24 & 378.78 & 506.37 & 201.35 & 398.46 \\
\hline Sakoli & 79.98232 & 21.07096 & 1505.40 & 253.30 & 356.78 & 234.23 & 417.71 & 330.50 & 404.19 & 382.68 & 365.24 & 202.00 & 332.58 & 350.83 & 486.87 & 278.80 & 442.86 & 315.50 & 476.46 & 221.73 & 354.41 \\
\hline Lakhandur & 79.88756 & 20.77721 & 1557.70 & 248.00 & 424.43 & 124.35 & 459.63 & 310.15 & 365.07 & 275.00 & 366.95 & 185.43 & 366.10 & 326.48 & 452.35 & 269.55 & 417.67 & 359.00 & 479.58 & 204.38 & 359.64 \\
\hline Lakhani & 79.82027 & 21.05558 & 1542.40 & 301.78 & 356.78 & 264.00 & 417.71 & 156.08 & 404.19 & 383.18 & 365.24 & 140.50 & 332.58 & 283.95 & 486.87 & 158.00 & 442.86 & 387.00 & 476.46 & 245.73 & 354.41 \\
\hline
\end{tabular}

Table.2 Seasonal rainfall observed in Rain gauge and TRMM data sets of Bhandara District (2009-2017)

\begin{tabular}{|c|c|c|c|c|c|c|c|c|c|c|c|c|c|c|c|c|c|c|c|c|c|}
\hline \multirow[t]{2}{*}{ Station } & \multirow[t]{2}{*}{ Lon. } & \multirow[t]{2}{*}{ Lat. } & \multirow[t]{2}{*}{ Annual } & \multicolumn{2}{|c|}{2009} & \multicolumn{2}{|c|}{2010} & \multicolumn{2}{|c|}{2011} & \multicolumn{2}{|c|}{2012} & \multicolumn{2}{|c|}{2013} & \multicolumn{2}{|c|}{2014} & \multicolumn{2}{|c|}{2015} & \multicolumn{2}{|c|}{2016} & \multicolumn{2}{|c|}{2017} \\
\hline & & & & $\mathrm{R} / \mathrm{G}$ & TRMM & $\mathrm{R} / \mathrm{G}$ & TRMM & $\mathrm{R} / \mathrm{G}$ & TRMM & $\mathrm{R} / \mathrm{G}$ & TRMM & $\mathrm{R} / \mathrm{G}$ & TRMM & $\mathrm{R} / \mathrm{G}$ & TRMM & $\mathrm{R} / \mathrm{G}$ & TRMM & $\mathrm{R} / \mathrm{G}$ & TRMM & $\mathrm{R} / \mathrm{G}$ & TRMM \\
\hline Bhandara & 79.6184 & 21.1696 & 1375.60 & 213.98 & 317.73 & 301.48 & 440.85 & 243.55 & 345.51 & 294.35 & 495.32 & 430.88 & 543.85 & 203.58 & 342.52 & 231.13 & 461.91 & 194.43 & 344.23 & 190.68 & 315.15 \\
\hline Mohadi & 79.6596 & 21.30912 & 1375.60 & 176.58 & 326.46 & 274.43 & 503.74 & 239.10 & 409.71 & 302.83 & 466.28 & 308.20 & 560.00 & 186.88 & 322.06 & 246.13 & 462.62 & 197.30 & 320.83 & 180.50 & 310.90 \\
\hline Tumsar & 79.73238 & 21.3833 & 1375.60 & 212.43 & 326.46 & 317.48 & 503.74 & 209.95 & 409.71 & 260.35 & 466.28 & 319.23 & 560.00 & 190.38 & 322.06 & 206.28 & 462.62 & 171.33 & 320.83 & 145.65 & 310.90 \\
\hline Pavni & 79.6541 & 20.80032 & 1346.30 & 195.53 & 369.87 & 384.95 & 556.40 & 291.98 & 422.77 & 386.85 & 477.83 & 436.35 & 569.83 & 166.53 & 311.65 & 207.98 & 516.77 & 193.53 & 410.08 & 215.15 & 338.78 \\
\hline Sakoli & 79.98232 & 21.07096 & 1505.40 & 237.55 & 367.84 & 396.38 & 416.31 & 297.28 & 380.82 & 314.83 & 503.52 & 435.98 & 563.04 & 261.00 & 366.92 & 301.58 & 458.71 & 252.13 & 361.10 & 217.88 & 318.89 \\
\hline Lakhandur & 79.88756 & 20.77721 & 1557.70 & 241.88 & 370.05 & 368.53 & 505.49 & 354.48 & 455.43 & 392.08 & 532.30 & 464.03 & 577.20 & 190.45 & 394.13 & 238.55 & 472.21 & 226.20 & 413.88 & 226.35 & 342.63 \\
\hline Lakhani & 79.82027 & 21.05558 & 1542.40 & 231.00 & 367.84 & 447.85 & 416.31 & 268.20 & 380.82 & 325.38 & 503.52 & 437.18 & 563.04 & 182.48 & 366.92 & 285.00 & 458.71 & 223.08 & 361.10 & 218.68 & 318.89 \\
\hline
\end{tabular}


Table.3 Statistical analysis of seasonal rainfall recorded in Rain gauge and TRMM data set (2000-2017).

\begin{tabular}{|l|c|l|c|}
\hline \multicolumn{2}{c}{ Rain Gauge station } & \multicolumn{2}{c|}{ TRMM } \\
\hline Mean & 272.21 & Mean & 408.51 \\
\hline Standard Error & 15.21 & Standard Error & 15.93 \\
\hline Median & 272.36 & Median & 396.58 \\
\hline Standard Deviation & 64.54 & Standard Deviation & 67.60 \\
\hline Sample Variance & 4165.75 & Sample Variance & 4569.97 \\
\hline Kurtosis & -0.78 & Kurtosis & -0.29 \\
\hline Skewness & 0.41 & Skewness & 0.66 \\
\hline Range & 224.90 & Range & 240.12 \\
\hline Minimum & 179.65 & Minimum & 322.30 \\
\hline Maximum & 404.55 & Maximum & 562.42 \\
\hline Sum & 4899.86 & Sum & 7353.27 \\
\hline Count & 18.00 & Count & 18.00 \\
\hline Confidence Level & 32.10 & Confidence Level & 33.62 \\
\hline (95.0\%) & & (95.0\%) & \\
\hline
\end{tabular}

Fig.1 Location of study area (Bhandara District, Maharashtra)
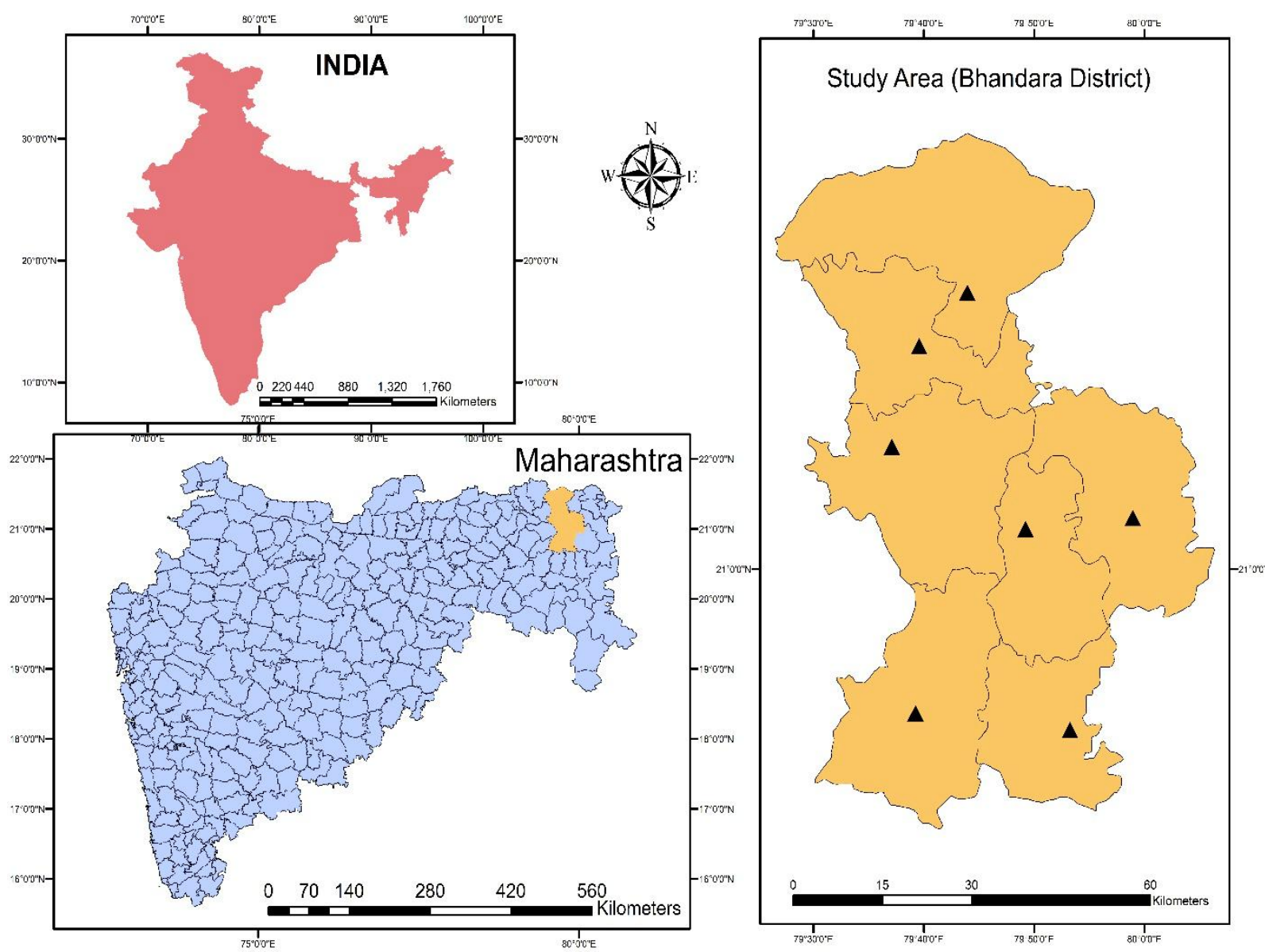
Fig.2 Scatter plot of seasonal rainfall observed in rain gauge station and TRMM rainfall data $(\mathrm{mm})$

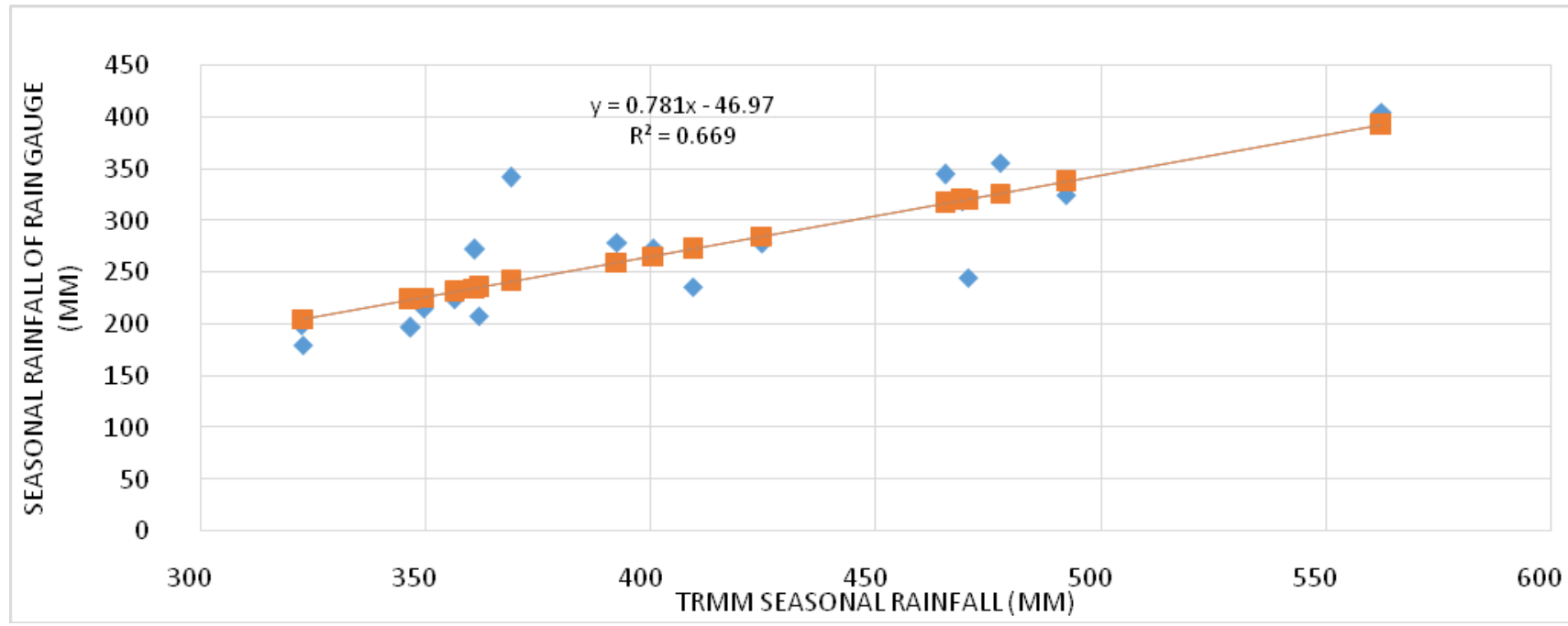

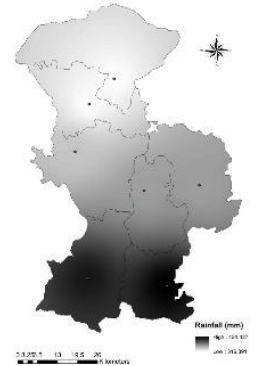

Fig. 3: TRMM (2000)

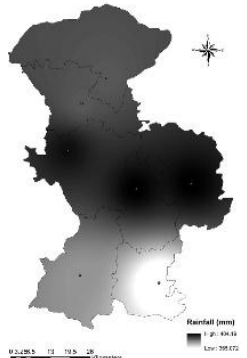

Fig. 7: TRMM (2002)

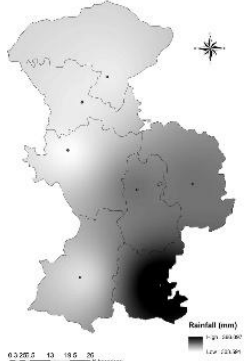

Fig. 11: TRMM (2004)

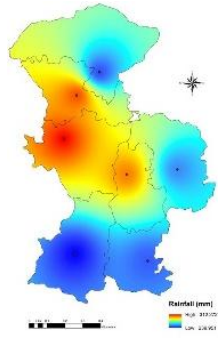

Fig. 4: RGS (2000)

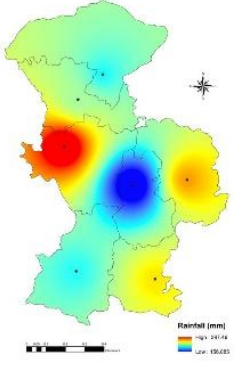

Fig. 8: RGS (2002)

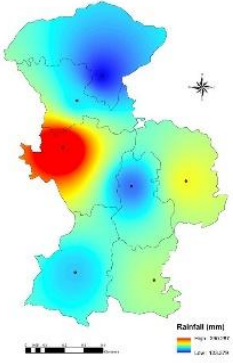

Fig. 12: RGS (2004)

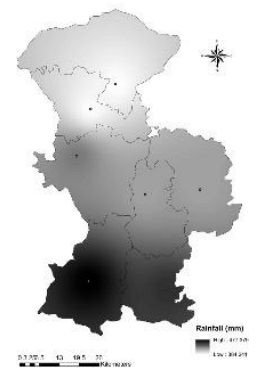

Fig. 5: TRMM (2001)

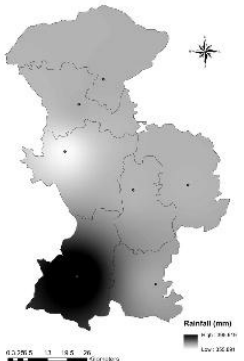

Fig. 9: TRMM (2003)

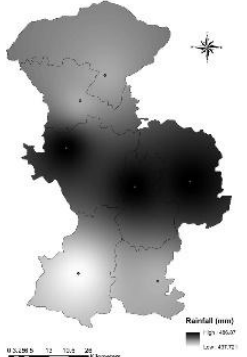

Fig. 13: TRMM (2005)

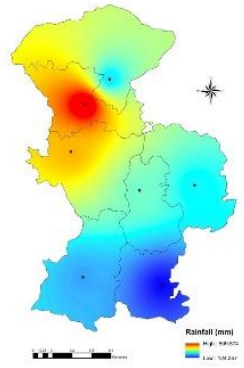

Fig. 6: RGS (2001)

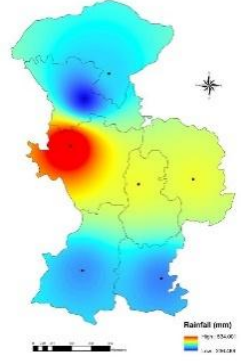

Fig. 10: RGS (2003)

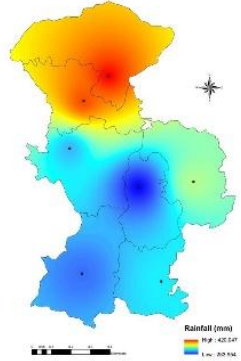

Fig. 14: RGS (2005) 


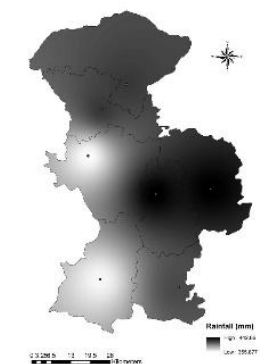

Fig. 15: TRMM (2006)

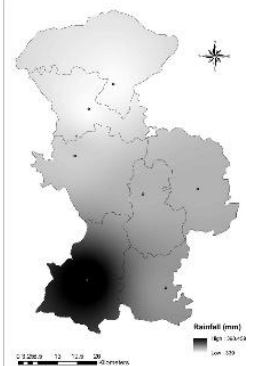

Fig. 19: TRMM (2008)

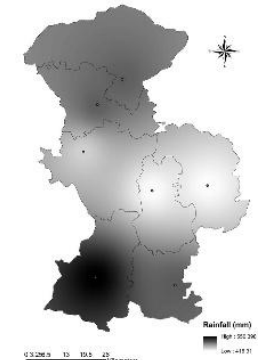

Fig. 23: TRMM (2010)

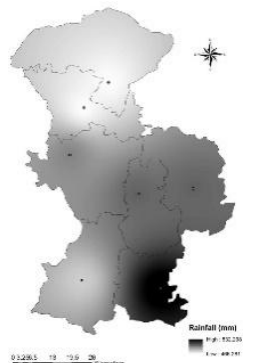

Fig. 27: TRMM (2012)

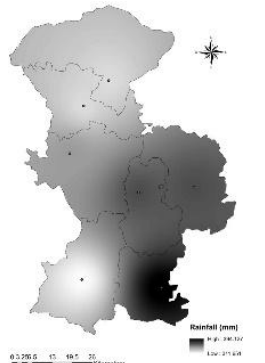

Fig. 31: TRMM (2014)

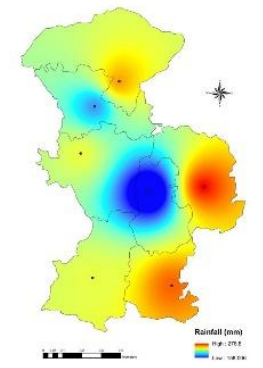

Fig. 16: RGS (2006)

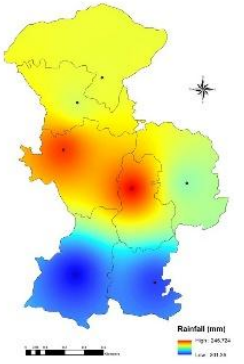

Fig. 20: RGS (2008)

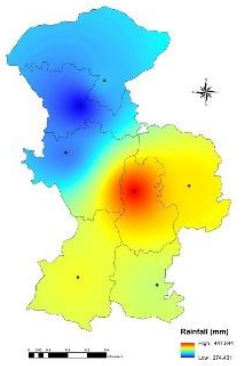

Fig. 24: RGS (2010)

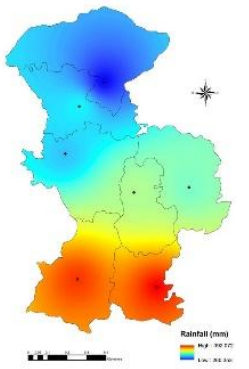

Fig. 28: RGS (2012)

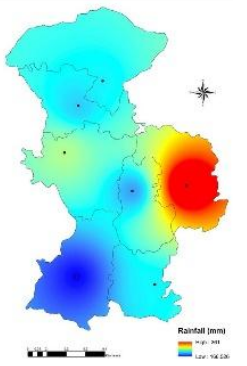

Fig. 32: RGS (2014)

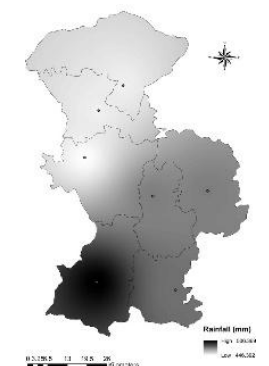

Fig. 17: TRMM (2007)

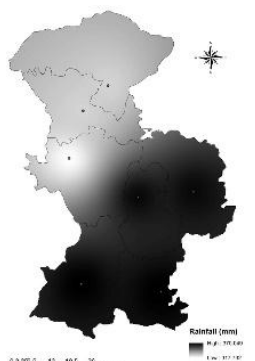

Fig. 21: TRMM (2009)

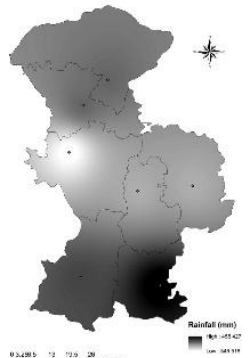

Fig. 25: TRMM (2011)

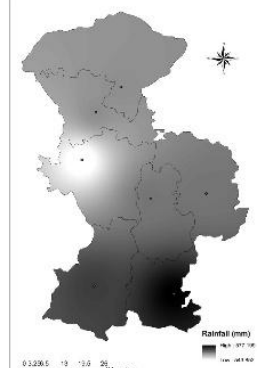

Fig. 29: TRMM (2013)

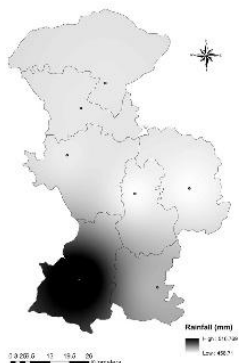

Fig. 33: TRMM (2015)

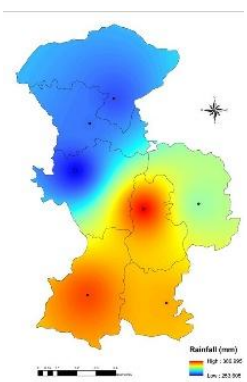

Fig. 18: RGS (2007)

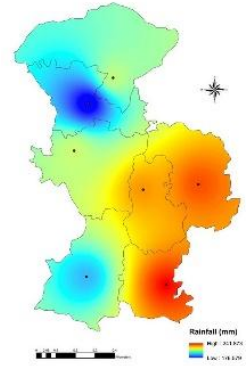

Fig. 22: RGS (2009)

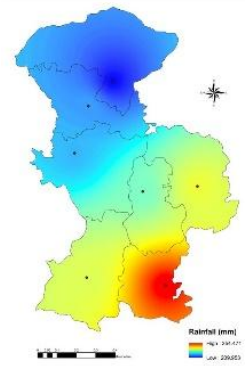

Fig. 26: RGS (2011)

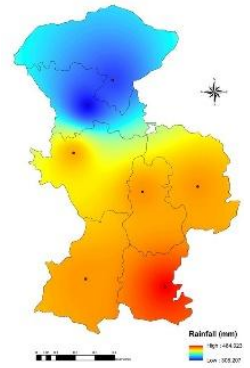

Fig. 30: RGS (2013)

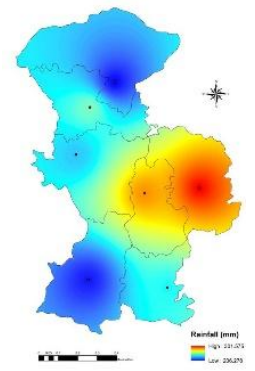

Fig. 34: RGS (2015) 


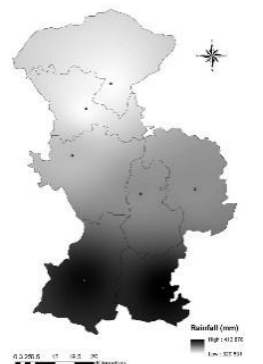

Fig. 35: TRMM (2016)

Fig. 36: RGS (2016)

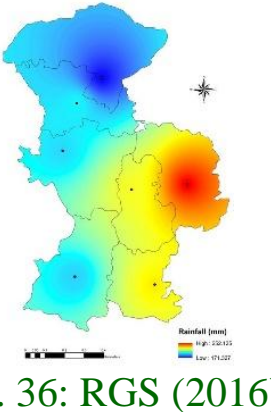

At present, there are still many difficulties in quantifying the precision of spatial rainfall distribution derived from the TRMM 3B43 rainfall data because of the lack of ground rain gauge stations at some remote regions in the country. Although the results (Fig. 3 - Fig. 38) show that TRMM rainfall data tend to overestimate rainfall, the two series (Table 3) show strong similarities especially for the years from 2000 to 2017. The satellite based rainfall products such as TRMM data have wide applications in hydrological simulation, water balance studies of different river basins on monthly and seasonal scales. However, there are some flaws in using TRMM data such as data may have underestimated or overestimated values in some years than the observed data set or unable to detect the extreme rainfall in a precise manner. As the TRMM mission has ended in April 2015, in future it is essential to develop new algorithms of satellite based rainfall estimation, on the basis of better space-time resolutions to overcome the deficiencies of single sensor methods (Michaelides, et al., 2009). Since satellite based precipitation data is now widely used by hydrologists and engineers in various disciplines, new revolutionary data for more accurate results are essential.

\section{References}

Fensterseifer, C.A. Qualidade das estimativas de precipitação derivadas de satélites na Bacia do Alto Jacuí - RS. 2013. 110 f.

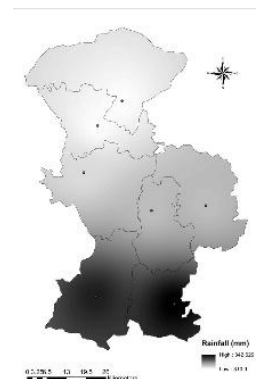

Fig. 37: TRMM (2017)
Fig. 38: RGS (2017)

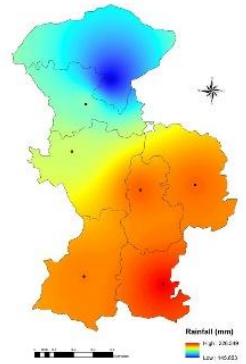

Dissertação (Mestrado em Engenharia Civil e Ambiental)-Universidade Federal de Santa Maria, Santa Maria, 2013.

Flaming, G.M. Measurement of global precipitation. In: International Geoscience and Remote Sensing Symposium. 9, 2004; Anchorage, AK, EUA.

Hiroshima, K. Rainfall observation from Tropical Rainfall Measuring Mission (TRMM) satellite. Journal of Visualization. (2) 1, p. 93-98, 1999.

Indu, J., and Kumar D., (2014) Evaluation of TRMM Precipitation Products over Indian Subcontinent. Int Arch Photogramm Remote Sens Spatial InfSci. 2014; 40(8):355.

Jamieson P, Porter J, Wilson D. A test of the computer simulation model ARCWHEAT1 on wheat crops grown in New Zealand. Field Crop Res. 1991; 27(4):337-50.

Kummerow C., (1998) Beamfilling errors in passive microwave rainfall retrievals. $\mathrm{J}$ Appl Meteorol., 37(4):356-70.

Kummerowa, C., Simpson, J., Thielea, O., Barnesa, W., Changa, A.T.C., Stockera, E. The Status of the Tropical Rainfall Measuring Mission (TRMM) after Two Years in Orbit. Journal of Applied Meteorology, v. 39, p. 1965-1982, 2000.

Massagli, G., Victoria, D., Andrade, R. Comparação entre a precipitação medida em estações pluviométricas e 
estimada pelo satélite TRMM. In: 5 ${ }^{\circ}$ Congresso Interinstitucional de Iniciação Científica - CIIC 2011 - 8, 2011.

Mishra A, Gairola R, Varma A, Agarwal V. Study of intense rainfall events over India using Kalpana-IR and TRMMprecipitation radar observations. Curr Sci. 2009; 97(5): 689-95.

Nandargi, S \& Mahto, Shanti Shwarup. (2016). Assessment of TRMM Rainfall Data (2001-2015) Over the Indian Region. Focus on Sciences. 2. 1-10.

NASA. National Aeronautics and Space Administration. GPM Mission Concept, 2011. http://pmm.nasa.gov/gpm.

Santos, A.S.P. Análise de desempenho dos campos de chuva estimados pelo satélite TRMM na Paraíba, para fins de modelagem hidrológica distribuída. 2014. 128 f. Dissertação (Mestrado em Engenharia Urbana e Ambiental) Universidade Federal da Paraíba, João Pessoa, 2014.

Signoretto M, Van de Plas R, De Moor B, Suykens J. Tensor versus matrix completion: a comparison with application to spectral data. IEEE Signal Process Letter. 2011; 18(7): 403-6.

Simpson J, Adler R, North G. A proposed tropical rainfall measuring mission (TRMM) satellite. Bull Am Meteorol Soc. 1988; 69(3): 278- 95.

Willmott C, Matsuura K. Advantages of the mean absolute error (MAE) over the root mean square error (RMSE) in assessing average model performance. Climate Res. 2005; 30(1): 79-82.

\section{How to cite this article:}

Sumedh R. Kashiwar, Usha R. Dongarwar, Manik Chandra Kundu, Sudarshan Awatade, Dileep Kumar, Lopchand Dongarwar and Hemkalyan Verma. 2018. GIS Mapping of TRMM Precipitation Data (NASA) over Bhandara District. Int.J.Curr.Microbiol.App.Sci. 7(08): 555564. doi: https://doi.org/10.20546/ijcmas.2018.708.061 